\title{
CRESPO, M. (Ed.). Filosofía trascendental, Fenomenolo- gía y Derecho Natural. Hildesheim: Georg Olms, 2018, 193 pp.
}

\author{
Adrián Bueno J unquero \\ Universidad Nacional de Educación a Distancia (UNED) \\ adrianbuenojah@gmail.com
}

Como resultado de un simposio organizado en Mayo de 2015 por el Instituto Cultura y Sociedad (ICS) de la Universidad de Navarra nace la obra que tengo el honor de comentar por su carácter novedoso y su ambiciosa pretensión dentro del restringido campo de la orientación fenomenológica del Derecho. Me remito a las palabras del mismo editor de la obra, Mariano Crespo, para ubicarla en el contexto temático donde se inscriben las distintas interrogaciones particulares: "se proponía profundizar histórica y sistemáticamente en las distintas teorías de la ley natural y de la racionalidad práctica" (p. 7) ${ }^{1}$. A la complejidad de esta empresa interdisciplinar ha de sumársele la intención de circundar alrededor de una posible inteligibilidad de la esencia de lo jurídico, examinada fenomenológicamente a través de aquellos elementos que son anteriores a toda disposición normativa y que pueden mentarse como "pre-positivos". A título de ejemplo podemos mencionar desde los estados de cosas que se encuentran en los actos del prometer, transmitir, etc. en el proyecto de Adolf Reinach, hasta la noción de ponderación presentada por Esteban Marín en su contribución, transitando por la reconstrucción sistemática que plantea Mariano Crespo sobre la corriente eidética que orienta el análisis del Derecho hacia descripciones formadas sobre el "método" trascendental de la fenomenología. En todo caso, no cabe duda alguna que

\footnotetext{
* Si no se dice lo contrario, las traducciones son del propio autor.

${ }^{1}$ Cabe recordar que ha sido editado por Ana Marta González y Alejandro G. Vigo.
} 
las investigaciones realizadas por el editor en los años previos a la publicación de la obra han contribuido enormemente a la celebración probablemente de la primera obra conjunta de fenomenología del Derecho en habla hispana².

La primera de las contribuciones corre a cargo de Marta Albert y se titula “Ética material de los valores y Derecho natural". Tras la publicación en 2004 de su obra titulada Derecho y Valor. Una filosofía jurídica fenomenológica - donde la autora expone la triple dimensión del obrar en su carácter jurídico-, esta vez se interroga por la posibilidad de hacer aterrizar todo Derecho natural sobre el suelo fenomenológico de la ética material de los valores elaborada por Max Scheler en su famosa obra El formalismo en la ética y la ética material de los valores. Ya en las primeras páginas el/la lector/a se encontrará con una definición de la "ética material de valores" estrictamente scheleriana que será fundamental para ubicar el punto de partida de la orientación fenomenológica. No ocurre lo mismo, sin embargo, con la definición de Derecho natural, que como bien recuerda la autora, no escapa fácilmente de la multiplicidad de interpretaciones elaboradas por la ciencia jurídica y la Filosofía del Derecho.

Retomando la idea aristotélica de las relaciones de necesidad en el ámbito social presente en la Ética a Nicómaco (p. 12), se ha de reconocer a la autora la lograda tríada de caracteres o notas esenciales presentes en toda manifestación de Derecho natural: (1) una doble genealogía de la necesidad que conecta con las cosas mismas a través de la "proyección en la vida social y en relación al problema de justicia" (p. 13) y que puede denominarse "a priori de necesidad" (p. 13); (2) como todo valor jurídico posee "un propio ser y un contenido material que puede ser conocido por el hombre" ( p. 13), este aparente carácter "per se" termina siendo, a juicio de la autora, contradictorio; (3) la concepción de la persona jurídica se halla envuelta de "un entramado de necesidades esenciales jurídicamente relevante" sobre todo porque "la dimensión relacional es estructural al ser humano" (p. 13). Es a través de esta tríada de caracteres o notas esenciales de todo Derecho natural que la autora identifica tres puntos de partida

\footnotetext{
${ }^{2}$ A pesar de las interesantes aportaciones a las cuestiones éticas, destacamos las dos contribuciones más recientes en materia de fenomenología el Derecho: Crespo, M. (2016). Fenomenología y filosofía del derecho. Pensamiento, 72 (274), 1247-1261; Crespo, M. (2016). Derecho Natural y Fenomenología. Una aproximación desde las ideas de Hans Reiner. En Cianciardo, J. \& Zambrano, P. (Coords.). Razón Práctica, Autonomía y Derechos Fundamentales (pp. 19-35). Ciudad de México: Tribunal Federal de Justicia Administrativa.
} 
presentes en toda teoría iusnaturalista: la existencia de necesidad en la "naturaleza de las cosas", el carácter objetivo y cognoscible de la justicia y el puesto central de la persona en el mundo jurídico (p. 14). Ello, además, le sirve de contrapunto para contrastar la teoría de Scheler con las bases del iusnaturalismo a través de una interpretación de la famosa máxima husserliana zu den Sachen selbst! basada en una visión eidética de la fenomenología de Ideas I, donde efectivamente Husserl conecta el retorno a las cosas mismas con la diferenciación de la actitud natural y la actitud propiamente fenomenológica. Solamente si nos orientamos a las cosas de un modo filosófico podemos desvelar sus mismidades, esto es, sus notas esenciales o esencia (das Wesen), manifestadas, eso sí, por medio de unas "conexiones de necesidad que, en ocasiones, son de necesidad esencial" (p. 15).

Tomando como referencia la compleja estructura de la intencionalidad que impregna tanto el campo noético como el noemático, no es posible hallar dichas conexiones esenciales de necesidad en el marco de una subjetividad cerrada. Precisamente porque "hay necesidad más allá de la convención" ( p. 15), retrotraer la ética material de los valores a la dación fenomenológica exige hacerla aterrizar sobre un determinado campo eidético de naturalezas ideales, accesibles, no obstante, por medio de la autodación que proporcionan las intuiciones y el encabalgamiento de actos que impregna la compleja estructura de la actividad fenomenológica. A propósito de estas cuestiones relativas al método fenomenológico, la autora identifica en esta referencia el cumplimiento del primer principio del iusnaturalismo, según el cual se muestra la existencia de necesidad en la "naturaleza de las cosas". Pero no será suficiente la constatación del carácter apriorístico y material de la ética scheleriana para fundamentar sus vínculos con el iusnaturalismo. Las dos tesis restantes encuentran asimismo cumplimiento a través de una mirada tendida sobre la noción de necesidad, explorada a través de su pertenencia a la razón y a las emociones (p. 17), ahondando, posteriormente, en las famosas leyes pascalianas del corazón que terminan arrojando al ser humano al horizonte de la objetividad de los valores. En este sentido, siempre corremos el riesgo de juzgar valorativamente una determinada concepción de lo justo, lo bueno, lo bello, etc. De ahí la importancia de orientarnos a través de la actitud fenomenológica hacia la región de las esencias o mismidades que también se presentan en el campo material de los valores, aunque no a través de un formalismo que resuena a neokantismo, sino a través de, como recuerda la 
autora, "el marco de una determinada experiencia personal que supone la superación de la resistencia que el mundo nos presta" (p. 19).

La reflexión prosigue con la determinación de los dos órdenes de valor diferenciados que hallan su primera manifestación en la obra de Scheler Trabajo y Ética (1899) a través del ejemplo del símil de los colores. En efecto, el orden primero "distingue los valores según la altura de sus depositarios" -orden formal_, mientras que el segundo "discrimina según las modalidades de valor" orden material- (p. 19). Como hay una determinada influencia del carácter apriorístico en la formulación de la ética material de los valores, también los órdenes encuentran, en su carácter a priori, una jerarquía de valores. Aquellos que se encuentran en el estrato más hondo y más bajo de todos se denominan valores sensibles (sinnliche Werte) y agrupan tanto lo agradable como lo desagradable. En el siguiente estadio superior hallamos los valores vitales (Lebenswerte) donde se enmarca lo noble, lo vulgar, lo bueno, lo malo, etc. A este tipo de valores les seguiría en ascenso los valores espirituales (geistige Werte) donde tendría lugar el denominado percibir sentimental espiritual y las preferencias, el amor o el odio espirituales (p. 20). Finalmente hallamos un último estrato de valor denominados "valores de lo santo y lo profano (das Heilig und das Unheilig)" (p. 20), que son los que se encontrarían vinculados a lo absoluto por su misma definición.

Una vez ubicados los correspondientes tipos de valores y justificada su dimensión apriorística, quedaría por responder a la pregunta de cómo podemos acceder a ellos en nuestra vida o experiencia cotidiana. Precisamente en esta dirección se encuentran los análisis de las siguientes páginas donde Albert incorpora la concepción scheleriana de la llamada teoría de la funcionalización, representada en términos de la remisión de lo apriorístico al flujo vivencial, operando, eso sí, a través del engranaje que vertebra la "experiencia natural y científica" (p. 21). Retomando la concepción scheleriana de la epojé husserliana basada en la noción de resistencia, reconduce la noción del valor a esta dimensión prerreflexiva que previamente se da en las experiencias de resistencia con respecto al mundo para terminar definiéndola en términos de "contenidos prelingüísticos" ( $p$. 229). Con la diferenciación entre el sentir que remite a los sentimientos no intencionales y el sentir propiamente intencional (p. 22) se describe este acceso o enlace primario que caracteriza a todo sentir intencional de los valores, sin intermediarios. De este modo se muestra el denominado “carácter subliminal de la 
fenomenología de Scheler" (p. 23) por medio de la inmediatez que proporciona el sentir intencional -y su referencia a la autodación-, pues la resistencia es tan poderosa que debemos enfrentarnos de alguna manera a los sentires encontrados. Así es cómo se produce el salto cualitativo hacia la necesidad de una reflexión "para que se nos vuelva objetiva esa percepción sentimental" (p. 23).

En este punto el/la lector/a encontrará minuciosos análisis sobre la concepción scheleriana de la intuición emocional y sus vínculos con la jerarquía de los valores, donde la autora remite al texto de Scheler Ensayo de fundamentación de un personalismo ético para recordar el carácter personalista de su ética, y por lo tanto, del a priori ya mencionado. Es especialmente destacable la reflexión que realiza sobre las características o notas esenciales del posible Derecho natural axiológico (pp. 27-38), donde las referencias a las obras de Scheler o las citas de algunos de sus contemporáneos otorgan a la investigación un rigor ineludible. Entre las referencias que la autora menciona sobre la posibilidad de incluir la ética material de los valores de Scheler en una suerte de iusnaturalismo axiológico, cabe mencionar la constatación de los llamados derechos morales o derechos naturales ( $p .28$ ), y sobre todo, el itinerario que se despierta en aquellos/as que pretenden transitar por la filosofía fenomenológica del autor cargando con el peso de la pregunta por la moralidad de su propuesta ética. De alguna manera se inicia con la pregunta por el lugar propio del iusnaturalismo en este estadio de moralidad y terminará por determinar cuáles son los modos operativos de la intuición fundamental en la constitución de lo jurídico, concluyendo que "la voluntad del legislador no determina lo que es o será Derecho" (p. 38).

Por mencionar algunos niveles o estadios de este itinerario ha de hacerse referencia a la idea del orden jurídico y a la idea del Derecho natural, analizada desde la jerarquía mencionada del valor y concluida con la descripción de lo que idealmente debe ser tal y como es percibido como algo desconectado de la normatividad porque "no precisa de una norma para ser realizado" (p. 29). A esta declaración le sigue la determinación de la idea del Derecho natural "en el penúltimo estrato de la moralidad" (p. 30), pues en el último se hallan "los valores de lo justo y lo injusto" ( p. 30). Otro de los ejemplos es la constatación de la imposibilidad de fundamentar el iusnaturalismo en la naturaleza humana a causa de la ya mencionada "naturaleza" de la legalidad que se nos torna accesible únicamente por medio de las intuiciones fenomenológicas. A través de una crítica frontal al proyecto kantiano, no solamente por el carácter formal de su propuesta 
ética sino por la noción de lo universalmente válido - al sustituir "el concepto de objetividad por el de validez universal" (p. 31) -, terminará afirmando que "el Derecho es una realidad cultural al servicio de la persona" ( $p .31$ ). A este ejemplo le sigue un tercer punto que confirma la no-permanencia del Derecho natural por medio de la teoría de la funcionalización, según la cual los hechos fenomenológicos se convierten "en estructuras de nuestras experiencias naturales y científicas" (p. 32). Naturalmente a partir de aquí no puede afirmarse una especie de permanencia del orden jurídico sino más bien su constante remisión a la variación. El cuarto ejemplo que menciona Albert guarda una estrecha relación con este último punto sobre todo porque desciende hasta las últimas capas de sentido y encuentra en la denominada variación del iusnaturalismo una variación "en función del ethos vivido por la comunidad" (p. 33). A través de esta afirmación constata que el Derecho natural es relativo a un ethos y objetivo para él, siendo, por lo tanto, "independiente de la misión del Estado en el mundo" (p. 35). Una última reflexión atiende finalmente a la idea del orden jurídico desde la des-platonización y la des-aristotelización de la noción de idea. Esto quiere decir, dicho en otras palabras, que las ideas no son ni antes ni después a la percepción sino cum rebus, esto es, "durante su funcionalización con las cosas" (p. 35). De acuerdo con esta visión cualquier aproximación fenomenológica consistiría en tomar un determinado posicionamiento o actitud con respecto a las cosas mismas por medio de la funcionalización, revelando, así, la esencia de las cosas mismas y permitiendo el enfrentamiento que origina la resistencia, lo que causaría, en última instancia, la posible reflexión objetivante que intentaría captar en última instancia la esencia de los valores jurídicos.

Finalmente, el ensayo culmina con una reformulación del Derecho natural de Scheler a través de lo que la misma autora denomina "saber jurídico del erizo" (p.38). Esta visión hallaría su fundamentación en la distinción Law in action y Law in Books originada por Pound en una contribución a la American Law Review, tornándose decisivo el carácter actual del Derecho en la medida en que se define como un obrar producto de la funcionalización de los valores jurídicos" (p. 38). De esta manera, adquiere un protagonismo singular la dicotomía iusnaturalismoiuspositivismo, pues necesita de una reconfiguración que pueda operar con la noción de los valores jurídicos entendidos como "elementos operantes en la praxis jurídica cotidiana (p. 44). 
En lugar de ubicar la producción de disposiciones normativas a la espalda de la persona, dice la autora, es un "estar a la espalda" del saber jurídico "del erizo" que «se trasluce no tanto en la adopción de una u otra interpretación de las normas, sino en algo aún más profundo, más bien en el mismo "ocurrírsenos" las ideas que están sobre la base de la posterior argumentación jurídica» ( $p .45$ ).

La contribución siguiente se titula La distinción entre la esfera de lo jurídico a priori y la esfera moral y viene realizada por el editor de la obra Mariano Crespo. En las primeras páginas hallamos el doble propósito de su contribución: el análisis del "rendimiento" de la crítica que uno de los sectores de la fenomenología del derecho realiza sobre el iusnaturalismo y su reconstrucción sistemática (p. 47). Dada la ausencia de un extenso bloque de autores contemporáneos a Husserl que hayan abordado exhaustivamente la cuestión del Derecho en clave fenomenológica, el análisis de Crespo toma en consideración la teoría a priori del Derecho de Adolf Reinach junto a las aproximaciones realizadas por Dietrich von Hildebrand. A propósito de esta empresa filosófica, nos advierte el autor, no nos hallamos ante un horizonte opaco de referencias que nos conduce a tratar la cuestión de un modo historiográfico, como si el Derecho fuera un conglomerado de hechos y tuviera por lo tanto que analizarse empíricamente. Por el contrario, estamos frente un detallado ejercicio filosófico que pretende devenir ante todo fenomenológico. En palabras del autor, la cuestión filosófica central es la confrontación de la peculiaridad de la esfera de lo jurídico "frente a las esferas axiológicas, moral y antropológica" (p.47). Del mismo modo que hallamos en el texto de Marta Albert una cierta presencia del campo eidético de la fenomenología gracias al apriorismo que se revela en la ética material de los valores, también adquiere cierto protagonismo la visión eidética del Derecho - predominante en lo textos de Reinach - en la medida en que sufre una cierta reconstrucción sistemática. Los modos a través de los cuales el autor tiende una mirada profunda sobre dicha corriente fenomenológica se originan en las denominadas "entidades jurídicas" (rechtliche Gebilde) a priori, responsables, en cierta medida, de las impresiones normativas, aunque efectivamente "no tienen propiamente carácter normativo" ( p. 47). Esta orientación se denomina eidética y analiza los modos a través de los cuales dichas entidades provocan —en el sentido laxo del términociertas impresiones de carácter normativo como pueden ser el carácter de obligatoriedad o el crédito de la transmisión, siempre analizadas bajo el esquema eidético de las conexiones esenciales. 
Ahora bien, lo cierto es que esta lectura fenomenológica coexiste con otro tipo de lecturas igualmente presentes en la comunidad fenomenológica. Como bien muestra el autor, también existe la orientación o dirección jurídica que toma la figura del jurista como fundamento para la examinación fenomenológica y la corriente de la dirección mundana que parte de la imbricación del fenómeno en la Lebenswelt. Incluso hay una tercera posible lectura fenomenológica denominada trascendental que se ocupa de la "comprensión o constitución del Derecho" (p. 48) y que encuentra su fundamentación en el itinerario que Husserl plantea en Ideas I sobre cómo se constituyen las objetividades de orden superior, las denominadas "comunidades intersubjetivas". Frente a esta visión de carácter trascendental forjada en el seno de una lectura esencialmente trascendental del proyecto husserliano, el autor dedica una serie de páginas a dilucidar las bases o los fundamentos de la mencionada orientación eidética (pp. 49-59) para exponer una reconstrucción que será sometida a una rigurosa comparación con la propuesta de Hildebrand.

Con la intención de exponer la fundamentación de la orientación eidética, el autor se interroga por los Elementos fundamentales de la orientación eidética al Derecho. La teoría a priori del Derecho de Adolf Reinach, partiendo del origen etimológico del término eidético - vinculándolo con el a priori- y estableciendo una distinción entre a priori formal y a priori material que ayudará a esclarecer el doble sentido implícito en toda orientación eidética del Derecho en tanto que ontología regional. Mientras uno de los sentidos nos remite a aquellas vivencias que se encuentran intencionalmente dirigidas a la esfera jurídica y por lo tanto se constituyen en ella, como, por ejemplo, dice el autor, "el prometer, el delegar, etc." (p. 50); el otro se retrotrae a las objetividades que son producto de estas vivencias y que usualmente podemos aprehender por medio de las mismas como por ejemplo la obligatoriedad que surge de cualquier vivencia o acto de prometer. La importancia de esta diferenciación hace justicia a la concepción que presenta Husserl en Ideas I sobre la constitución de las objetividades, tanto de rango superior como inferior. Precisamente porque a cada ámbito de objetos le corresponde una esfera de contenido apriórico, dice el autor, al Derecho le corresponde "una legislación especial a priori" (p. 50). Este es precisamente el objeto de investigación de Adolf Reinach en la obra Los fundamentos a priori del Derecho civil, donde Reinach pretende "poner de manifiesto la peculiaridad ontológica de estas entidades cuyo ser es independiente de su captación por los sujetos 
conscientes" ( p. 50). De alguna manera se constituyen como todos en los cuales se dan ciertos momentos no-independientes que podríamos denominar estados de cosas. Diríamos que una promesa puede extinguirse por medio de una renuncia, siendo la posibilidad de la renuncia un elemento constitutivo o nota estructural de cualquier acto de prometer intencional. De esta manera, dice Crespo, este tipo de necesidad no es aprehensible en términos fenomenológicos, sino que en cierta medida se dirige hacia los estados de cosas de un modo absoluto y necesario, abarcando "a todo lo que es de tal especie" (p. 51). En este sentido, la aproximación eidética que se orienta fenomenológicamente hacia las leyes simples del ser (schlichte Seinsgesetze) constituye la teoría a priori del Derecho que presenta Reinach.

No cabe duda alguna que esta teoría denominada eidética material sale al encuentro en el ámbito de la orientación eidética de lo jurídico y no en la teorización de la legalidad positiva. A través del examen en primera persona de los estados de cosas impresos en las entidades jurídicas se podría llegar a describir fenomenológicamente lo que entendemos por Derecho natural. Digamos que al/a aventurado/a fenomenólogo/a no le sirve la mera voluntad del legislador para comprender la esencia de lo jurídico. Para comprender la esencia del Derecho natural uno ha de arrojarse a la exploración del iusnaturalismo partiendo de su originaria manifestación, presentada, como ya se ha mencionado al inicio de la obra, a partir de una determinada noción de "la naturaleza de las cosas". En las páginas que siguen, el autor expone hasta cuatro sentidos posibles de la expresión "naturaleza de las cosas" para dar a conocer hasta qué punto la teoría a priori del Derecho presentada por Reinach se identifica con el uso corriente del iusnaturalismo clásico: (1) una "naturaleza de las cosas" "está presente en la tradición del iusnaturalismo clásico, el cual está ligado a una determinada metafísica de la creación" (p. 52); (2) también puede referirse a la "naturaleza fáctica de las cosas en el sentido de las características o propiedades de los objetos que regular" (p. 52); (3) la "naturaleza de las cosas" se hallaría implícita en la "teoría de la naturaleza de las cosas", es decir, "a partir de la naturaleza del hombre, pretende fundar el mismo Derecho para todas las épocas y para todos los pueblos" ( p. 53); (4) la "naturaleza" sería la relación medio-fin que se halla en la idoneidad de las entidades para "funcionar como medio para conseguir ciertos fines" (p. 53-54). 
La exposición de los sentidos mencionados le sirve al autor para identificar el primero de ellos con la concepción que presenta Reinach sobre las entidades jurídicas, sobre todo porque éstas son independientes del Derecho positivo. No cabe duda alguna que el resto de connotaciones o sentidos del término escaparía a la denominada orientación eidética del Derecho. Aunque lo interesante de este análisis se halla precisamente en la manera en que el autor consigue entrelazar las diferentes reflexiones que Reinach presenta en algunas de sus obras y no tanto en la coincidencia del sentido de "naturaleza"; si bien la coincidencia despierta una necesidad de exponer las diferencias entre iusnaturalismo e iuspositivismo que Reinach presenta en los Fundamentos a priori del Derecho civil. Se pone el énfasis precisamente en las denominadas simples leyes del ser porque constituyen el origen de aquellas relaciones jurídicas reveladas a partir de determinadas vivencias jurídicas como la transmisión de la propiedad, con todas las obligaciones y condiciones de extinción que de ellas se pueden derivar. A modo de resumen, dice el autor, "se trata, por tanto, de proposiciones teoréticas - no normativas- fundadas en la esencia de ciertos actos y situaciones." (p. 55). Incluso afirmará en las siguientes páginas que existen otras diferencias entre la teoría del Derecho a priori de Reinach y el iusnaturalismo que permiten entablar debate con Hildebrand, originada, la segunda de ellas, a partir del hipotético poder creador que no termina de satisfacer al Derecho natural -es el poder creador quien origina la entidad jurídica que establece la mayoría de edad a los dieciocho años-. De esta manera, dice Hildebrand, hay entidades jurídicas “que no existirían si no hubiera Derecho positivo" (p. 57), mientras otras no derivan directamente de las disposiciones positivizadas. De aquí se observa una diferenciación fundamental entre las leyes del Derecho positivo - vinculadas a las denominadas simples leyes del ser "a las que subyacen Anpassungsakte"- y las leyes positivas -relativas a las proposiciones normativas donde se encuentran los Bestimmmungsakte- (p. 57).

A la riqueza expositiva de este apartado sobre Reinach y su teoría a priori del Derecho le sigue un análisis sobre el rendimiento de la crítica de Reinach al iusnaturalismo titulado "La especificidad de la esfera de lo rechtlich a priori frente a la esfera moral" (p. 59-61). Que el autor solamente le dedique dos páginas no es síntoma en ningún caso de superficialidad. Recordemos que el mismo Reinach lo condensa "en siete apretadas páginas" (p. 59). A los ojos del autor, su muerte prematura seguramente le cortó las alas, paralizando su prometedora carrera. 
No obstante, que carezca de una explicitación sobre la noción de naturaleza imbricada en todo iusnaturalismo no debe ser un impedimento para conocer en profundidad la esfera de lo jurídico. Es aquí donde radica precisamente uno de los mayores logros que se le deben atribuir al autor por haber conseguido dar visibilidad a un artículo de Hildreband del año 1974. Diferenciando dos sentidos de Recht, se le atribuye a las entidades jurídicas (rechtliche Gebilde) el sentido de "las vinculaciones legales que surgen de determinados actos" (p. 60) -originarias de las simples leyes del ser-, al mismo tiempo que se le atribuye el sentido de Derecho natural -que sí tienen un carácter normativo-. Llegados a este punto, el autor termina explicando la diferencia entre la esfera de lo jurídico y la esfera de lo moral a través del ejemplo de la Verbindlichkeit (vinculación) en su dimensión jurídica y moral. Digamos que la rechtliche Verbindlichkeit - vinculación legal- a diferencia de la moralische Verpflichtung -obligación moral- necesita del destinatario para efectuarse, mientras que la última no necesita su aparición porque se funda en un determinado orden de valores (p. 60-61).

Frente a la complejidad de las reflexiones, el autor no deja de esclarecer las posibles diferencias entre iusnaturalismo y teoría a priori del Derecho. Para ello recuerda la diferencia entre lo jurídico y lo moral recién esbozada, aunque también, y sobre todo, la orientación fenomenológica que presenta Hildreband a través de una tríada de expresiones que pretenden aportar algo de luz a la cuestión: (1) "es preciso comprender la peculiaridad de los derechos naturales frente a los derechos a priori, a los derechos positivos y a los derechos morales" (p. 61); (2) "es necesario esclarecer la relación entre Derecho a priori y Derecho positivo"; (3) "hay que explicitar la relación entre derechos positivos y derechos morales" (p. 61). A lo largo de las últimas páginas de su contribución el autor llega a una serie de conclusiones que le permiten afirmar que "el Derecho positivo tiene que tener en cuenta el punto de vista moral" (p. 65) y confirmar así la separación ya esbozada entre lo jurídico y lo moral (p. 65). Finalmente, el autor concluye su aportación reconociendo el mérito que debe atribuírsele a Reinach por haber abierto una "tercera vía frente al positivismo jurídico y al iusnaturalismo" (p. 67).

La tercera contribución se titula "A defence of natural law based view of human rights" y corre a cargo de Cheikh Mbacke Gueye, doctor en Filosofía por la Internationale Akademie für Philosophie del Principado de Liechtenstein, donde trabaja cuestiones relativas a la filosofía fundamental, la ética práctica y los derechos humanos. El autor sostiene la importancia de tomar en consideración a 
Charles Beitz para la dilucidar un sentido filosófico del Derecho natural a través de una determinada concepción de los derechos humanos. A través de un enfoque práctico, recuerda Mbacke, el análisis de Beitz puede proporcionar "una doctrina política construida en aras a jugar un juego determinado en la vida política global" (p. 71). Frente a una concepción naturalista de los derechos humanos, nos encontramos ante una determinada idea de pertenencia que remite a la dignidad humana ( $p .72$ ). Precisamente porque la perspectiva del naturalismo en materia de derechos humanos "no incorpora o hace uso de las consideraciones sobre funciones discursivas de los derechos humanos en el marco de la práctica existencial" (p. 71), tornándose insuficiente "para iluminar el problema de la contribución" ( $p .71$ ) y a su vez conteniendo una determinada materia naturalizada que se retrotrae a las protecciones "ya explicitadas en la doctrina internacional de los derechos humanos" ( p. 71), no puede proporcionarnos un suelo suficientemente sólido para exponer una fundamentación por esa vía.

Tras rechazar la perspectiva naturalista de los derechos humanos, el autor toma en consideración una teoría de Regina Kreide (2013) por su distanciamiento con respecto a los discursos naturalistas. Dicha teoría toma como base de sus argumentaciones la concepción naturalista del ser humano, según la cual ésta exige, ex lege, "la justificación de tener derechos humanos" (p. 72). Duda de la posible continuidad de un Derecho natural que pueda ofrecer una solución a la controversia y finalmente critica la visión del Derecho natural por no incorporar una diferencia entre valores y derechos ( pp. 71-72). En este contexto de ausencia de fundamentación y desaparición de referentes, Mbacke clasifica en dos categorías las diferentes críticas dirigidas al Derecho natural desde la perspectiva de los derechos humanos. Mientras que la primera se ocupará de la naturaleza y de la fundamentación de los derechos humanos, la segunda vendrá motivada por la crítica que interpreta los derechos humanos como atemporales, aunque aceptando, al mismo tiempo, los new rights. El autor adelanta cuál será su postura al respecto cuando señala "que la atemporalidad de los derechos humanos, en la medida en que se ocupa primeramente y principalmente con los derechos básicos y fundamentales como el derecho a la vida, a la libertad, a la propiedad, etc., no pueden descalificarse tras la emergencia de los nuevos derechos" (p. 72).

Entablando un diálogo profundo con una concepción del Derecho natural que entiende los derechos humanos en términos de "propiedades naturales" ( p. 73) se introducen elementos metafísicos y religiosos de suma importancia como por 
ejemplo el atributo de haber sido creados "a imagen de Dios" (p. 73). Ello permite al autor hacer mínimamente explícita su propia concepción de los derechos humanos. Como únicamente pretende esbozarla ( $p$. 73) no hallamos un extenso tratamiento a lo largo de las investigaciones, aunque sí una ligera exposición de la misma: "Ios derechos humanos existen independientemente de nuestra cognición o conocimiento" (p. 73). Pero lo más interesante viene presentado a continuación cuando expone que "se encuentran arraigados en la esencia de la persona humana, particularmente en su valor inherente. Llegamos a conocer este valor inherente y los derechos que resultan de él a través de la primera forma racional de conocimiento: la intuición" (p. 73). Tal vez hubiera sido enriquecedor hallar aquí un despliegue fenomenológico de la intuición para comprender qué entiende el autor por intuición y en qué medida podemos intuir este valor inherente. En cualquier caso, el ensayo del autor hace justicia a la exposición de las críticas que recibe la perspectiva naturalista de los derechos humanos. Es comprensible, por lo tanto, su carácter introductorio. Tengamos en cuenta que en la perspectiva naturalista se halla implícita una determinada concepción de la moralidad, en lugar de aprehender, siguiendo a Ricoeur, la dignidad que tanto nos hace humanos (pp. 73-74).

En el siguiente apartado, titulado "What is a Foundation?", hace aterrizar el término foundation - vinculado a los derechos humanos- sobre la noción de dignidad. La referencia fundamental de las primeras exposiciones que realiza Mbacke en este apartado es Jeremy Waldron (2015), quien subraya cuatro posibles interpretaciones de la noción de foundation en relación con el objeto que pretende ser fundado. Brevemente podríamos interpretarla como una materia de la historia y la genealogía a través de la cual algo ha sido fundado. Otra opción es entenderla, dice Waldron, como producto de la fuente a la que hace referencia y desde donde se origina. También podría lo fundado derivarse lógicamente de lo fundante o participar de una lógica indispensable sin la cual no tendría sentido terminar siendo fundada (p. 74-75). De las cuatro posibilidades ha de tomarse como referencia, según el autor, la segunda de ellas, esto es, aquella que hace referencia a la fuente desde donde se origina. Es la fuente la que otorga legitimidad y permite que se origine la foundation en la medida en que "captura lo que uno podría tener en mente mientras habla sobre la dignidad humana en términos de una fundamentación de los derechos humanos" (p. 75). 
Tras los análisis relativos a la foundation y su interpretación aplicable al campo de la dignidad humana, retoma una reflexión un tanto sugerente de Beitz dirigida a entender la fundamentación de los derechos humanos en términos de una fundamentación limitada (narrow foundations) (p. 76). Así es cómo las teorías naturalistas impregnan los seres humanos, despliegan la cuestión del límite y la incorporan al mismo proceso de fundamentación. Contrariamente a esta tendencia, el autor sostiene que la dignidad humana se manifiesta originariamente por medio de diferentes fuentes en la medida en que "abarca dimensiones de la vida humana y los derechos humanos" (p. 77). A continuación traza una reflexión comparada entre J osef Seifert (1998) y la teoría a priori del Derecho presentada por Adolf Reinach que termina siendo muy enriquecedora para dar continuidad a las diferentes contribuciones temáticas. El autor sostiene que los derechos humanos, dentro de la categoría de los cuatro derechos a los que alude Seifert, "derechos humanos, derechos naturales, derechos a priori y derechos positivos" (p. 76), son de una naturaleza distinta a los teorizados por Reinach, pues no pueden ser revocados por ningún legislador. No será hasta la determinación de la variedad de los derechos humanos que pueden originarse en las diferentes fuentes de la dignidad humana que el autor terminará por retomar la concepción de Seifert sobre las cuatro fuentes de la dignidad humana: (1) la esencia, el ser y la sustancia de la persona; (2) conciencia y actualización de la personalidad; (3) dignidad moral; (4) relaciones extrínsecas y regalos individuales de diferentes tipos.

En las siguientes páginas el autor profundiza sobre cada una de las fuentes, sometiéndolas a una visión comparada y variando así sus posibles interpretaciones en la tarea principal de definir los denominados derechos humanos ( pp. 7679). Una última reflexión toma como objeto de análisis los denominados new rights a través de la crítica frontal al carácter descalificador que atiende a la supuesta atemporalidad de los derechos humanos. En este punto parece volver a retomar una visión crítica con respecto al iusnaturalismo clásico según el cual “las normas de los derechos humanos y los valores son derivados del Derecho natural" ( $p .80$ ). Mientras se sostiene que los derechos humanos no deberían ser violados "están constantemente siendo violados: es un hecho empírico" (p. 80), una determinada concepción de los derechos humanos domina el carácter atemporal que se encuentra implícito en todas las disposiciones normativas. A través de este tipo de reflexiones el autor introduce los denominados new rights y 
asegura que no pueden descalificar la atemporalidad de los derechos humanos «en la medida que siempre habrá "nuevos" derechos dados inevitables y con fiabilidad inherente y perfectibilidad de las personas humanas y las sociedades» (p. 81). Posteriormente incorpora la visión de J ames Griffin —basada en que sólo los derechos humanos básicos son temporales mientras que los derivados no lo son ( $p .81$ ) - y la contrasta con Matthew Liaw - quien defiende la compatibilidad de la atemporalidad de los derechos humanos y la de los new rights ( p. 81)-, conclusiones sobre cómo deberíamos encaminarnos hacia el futuro: "los derechos humanos necesitan fundamentaciones sólidas, sustanciales y profundas que no puedan ser halladas en el acuerdo de una comunidad internacional" (p. 84).

Un análisis que resuena a fenomenología está relacionado con Adolf Reinach y Edmund Husserl y se titula "Sobre la racionalidad del deber social. Reflexiones sobre el deber social con base en observaciones en Edmund Husserl y Adolf Reinach." Doctor en Filosofía por la UNAM e investigador invitado en el HusserlArhiv de Köln, Esteban Marín Ávila hace confluir muy detalladamente en su aportación la concepción husserliana de "las proposiciones normativas que implican valoraciones" ( $p$. 87) con "las investigaciones de Reinach sobre la esencia de los actos sociales" ( p. 87). Por lo que respecta a la investigación centrada en las proposiciones normativas de Husserl, cabe destacar la acertada continuidad que traza el autor sobre las cuestiones planteadas, partiendo de la concepción esbozada en las Investigaciones Lógicas donde se afirma que la exigencia propia de deber es que un juicio sea válido o correcto; prosigue con un análisis del carácter dóxico de la creencia para dar a conocer "las propiedades del valor" (p. 91). En este campo de problemas nos topamos en las lecciones de ética de 1908 y 1914 donde los problemas relativos a la axiología formal son tratados en paralelo a la lógica formal (p. 92).

Posteriormente Marín se interroga acerca de los modos o formatos a través de los cuales Husserl expone las implicaciones de la denominada axiología formal, presentando la noción de silogismo axiológico y vinculándola con los silogismos prácticos. Destaca la noción de ponderación por hacer posible que mi estimación sobre algo -impregnada de consideraciones y otras aproximaciones dóxicas-, se vincule con el valorar a través de hacer visibles sus posibles cualidades axiológicas. De aquí se afirma que algo valorado puede, no obstante, someterse a variación, "puede alterarse dependiendo de las premisas en las que se sostiene la ponderación" ( p. 94), sin olvidar las importantes conexiones que despierta la 
ponderación con la racionalidad práctica, y por lo tanto, con las intenciones prácticas particulares que intentivamente se dirigen a algo "que o bien existirá o bien seguirá existiendo en virtud y a través de esta intención" ( $p .95$ ). Y es justo en este punto que Marín sostiene la importancia de atender a las valoraciones en la medida en que "las intenciones prácticas están motivadas por valoraciones" ( $p$. $96)$, redefiniendo, incluso, la teoría de las proposiciones normativas constitutivas de la fenomenología estática (pp. 96-98).

Asumiendo que “todo deber auténtico implica la asunción de un bien” (p. 98), Marín expone la problemática principal que vertebra el eje central de su contribución, pivotando alrededor de los deberes que podríamos denominar sociales, o que, al menos, surgen de interacciones sociales cuya naturaleza puede ser la jurídica. Algunos de los ejemplos empleados por Mariano Crespo, como puede ser el prometer, el transmitir, etc., serían objeto de investigación de esta segunda parte de la contribución de Marín. No debe perderse de vista que, como asegura el autor, lo importante es dilucidar si un deber de estas características implica asimismo la asunción de un bien como el resto de deberes que han sido previamente investigados. De esta manera, el autor recuerda el concepto de acto social presentado por Reinach en el contexto del Anspruch, es decir, de las pretensiones, para identificar la suerte de actos que se manifiestan en este marco interactivo propio de la cotidianidad con el otro. Es comprensible que actos como pedir, ordenar u obligar se hallen en el punto de mira de las reflexiones de Marín, sobre todo si tenemos en cuenta que las pretensiones de fondo no son de la misma naturaleza que los deberes expuestos al inicio de su contribución. Tomando en consideración la cuestión capital del consentimiento, el autor termina afirmando que la eficacia de los actos sociales depende de la aceptación de los mismos (p. 100).

No le sorprenderá a el/la lector/a que el autor remita a la teoría de Reinach en relación con el prometer en la medida en que toda aceptación procede de una promesa (p. 101). De igual modo probablemente le será familiar el elenco de ejemplos cotidianos que emplea el autor para esclarecer cuáles son las relaciones entre los deberes que se desprenden de este tipo de actos sociales. Aunque esta pregunta particular venía motivada - recuerda Marín en las últimas páginas- por la interrogación general de si aquellos deberes derivados de los actos sociales también implican "necesariamente la asunción de bienes" (p. 103). A este respecto el autor responde retomando la noción de capacidad social que podría 
desprenderse de la esencia de la persona: "el deber social supone en tanto que tal la asunción de que es bueno disponer de capacidad social" (p. 105). Finalmente concluye asegurando que el cumplimiento o incumplimiento de una obligación "dependerá de la ponderación de todos los bienes y males en juego, incluyendo la capacidad social" (p. 106), sin desatender, en ningún momento, la experiencia directa con el otro en el marco de la facticidad y la cotidianidad. Este último aspecto confiere al texto de Marín una cierta familiaridad no exenta de rigor, haciendo de su contribución una exploración fenomenológica de primer orden, con sus descripciones, y sobre todo, sin desatender las reflexiones llevadas a cabo por Husserl y sus contemporáneos.

De la compleja cuestión del deber encontrará el/la lector/a un texto cuyo título ya es suficientemente sugerente de por sí: “La libertad del derecho penal: ¿de qué hablamos cuando decimos libertad?". El atractivo del título adquiere una importancia singular si lo enmarcamos en el telos de la investigación: investigar el verdadero marco de la libertad tratado a través de la analítica de la libertad y la síntesis de la libertad (p. 111). Pablo Sánchez-Ostiz es catedrático de Derecho Penal de la Universidad de Navarra y doctor en Filosofía, por lo que no sorprenderá el carácter interdisciplinario de sus investigaciones. Se inicia la reflexión con la definición presente en la legislación aplicable sobre la noción de libertad, entendida como un "bien jurídico protegido" (p. 112) y a su vez tratada en términos de base "para la atribución de responsabilidad" (p. 112) u "objeto de pena" ( $p$. 112). Por “legislación aplicable" entiéndase aquí la disposición normativa aplicable en cada caso, teniendo en cuenta el principio legal de la jerarquía de normas que atribuye a la Constitución el carácter de norma suprema. Gracias a esta jerarquía la libertad adquiere un rol fundamental en la exposición del Preámbulo y del primer artículo del corpus jurídico. Todos estos aspectos son analizados minuciosamente en comparación con el contenido de otros preceptos normativos de suma importancia. Vale decir que en ningún caso se olvida la importante cuestión del sentido común por sus importantes nexos con la constitución del orden. Incluso va más allá cuando afirma: "nos entendemos cuando decimos de alguien que es libre" (p. 113).

Sánchez-Ostiz alude en diversas ocasiones a la polisemia que parece hallarse en el tratamiento de cuestiones legales imbricadas en la cuestión de la libertad como por ejemplo el aborto libre, la libertad de expresión y un largo etcétera. En cualquier caso, el planteamiento de la cuestión exige diferenciar entre la noción 
de libertad y la de libre albedrío. El autor encuentra que una interpretación psicológica sobre la libertad dirigida a comprender la misma libertad en términos de una libertad psicológica sería "pasar por alto que hay una libertad más radical y básica, condición del Derecho y la Moral, de todo el ámbito de la actuación humana" (p. 114). Sin ofrecer una solución definitiva a esta cuestión preliminar, Sánchez-Ostiz se encarga de recuperar algunas corrientes como el parcialismo, el suposicionismo y el agnosticismo que impregnan las diferentes esferas del conocimiento ( pp. 114-115) para terminar distinguiendo una noción de libertad cuya fundamentación "se opone a necesidad" (p. 116). Tampoco podemos olvidar, dice el autor, la libertad política "dentro del mundo de lo moral como no necesario" ( p. 116) o la libertad de elegir "en cuanto capacidad de optar en cada conducta" ( p. 116), lo que dicho de forma más concreta y precisa sería el denominado libre albedrío. Incluso hallamos una última tipología de libertad denominada libertad básica que se identifica con "el «ser libre», y no meramente con el querer o la elección" (p. 117).

En el trasfondo de todas estas cuestiones hallamos algunas críticas metodológicas a la primera versión de libertad - opuesta a la necesidad ( $p$. 117) - que el/la lector/a encontrará fundamentales para introducir la mencionada analítica de la libertad (pp. 118-121). La riqueza expositiva del texto presentado por el autor se torna cada vez más visible cuanto más profundiza sobre los vínculos entre libertad y acción (pp. 118-119) - por ejemplo, a través de la acción en prospectiva y la acción en retrospectiva-, diferenciando la libertad perteneciente a la identidad del sujeto y la libertad que se posee, es decir, la que es objeto de tenencia. A esta empresa de rigor ha de añadírsele sin lugar a dudas la doble diferenciación entre libertad en prospectiva-libertad en retrospectiva y libertad innata-libertad adquirida (p. 121) representada por una relevante imagen gráfica que introduce finalmente la denominada síntesis de la libertad. Para comprender esta teoría el autor toma en consideración primeramente la libertad antropológica, basada en el hecho "que el ser humano se rige por normas o pautas" ( $p$. 122), sometiéndola al doble flujo de libertades recién mencionado, lo cual aporta algo de luz a la cuestión de la naturaleza de las distintas libertades al mismo tiempo que revela el carácter limitante presente en toda reflexión sobre la libertad. Tras el análisis del alcance de la libertad antropológica, Sánchez-Ostiz desciende progresivamente hasta topar con la elección básica o volición ( pp. 128133), fundada sobre una determinada orientación acerca de los modos a través 
de los cuales se manifiesta la misma voluntad, sin olvidar sus relaciones con la facultad intelectiva del sujeto y el inmenso horizonte del conocer (pp. 129). Análogamente a la metodología empleada para conocer la naturaleza de la libertad antropológica -empleando el gráfico de la doble diferenciación de libertades- también presenta un análisis detallado sobre los vínculos entre esta elección básica y la libertad en retrospectiva, innata, etc., hasta dar con una definición suficientemente sólida como para tenerla en cuenta: “la elección básica o volición no permite alcanzar un sentido completo de la acción humana, sino que es preciso completar su contenido, tanto en el aspecto intelectivo como en el volitivo." (p. 133).

Posteriormente se interroga por la elección moral o voluntariedad ( $\mathrm{pp}$. 133139) desde la teoría de la imputación que completa a la volición ( p. 135) con sus inevitables nexos a la teoría de la pena, la responsabilidad, y sobre todo, a la compleja estructura del juicio de culpabilidad que fundamenta toda privación de libertad en el marco de la legislación penal. En esta reflexión menciona también la propuesta de Welzel y su famoso "poder actuar de otro modo" ( p. 137) hasta llegar a las denominadas libertades políticas (pp. 139-141). A diferencia de la libertad antropológica, las políticas son “de carácter adquirido y operan en la prospectiva" (p. 139). Concluyendo con la denominada síntesis de la libertad, el autor recuerda la intención inicial que motivó el ensayo: “pretendía superar la fragmentación propia de la analítica de la libertad, y dar con el sentido y contenido de esta realidad" (p. 141). Lo hace mencionando algunas consecuencias derivadas de este planteamiento penal como puede ser la forma inductiva a la que se llega a la libertad cuando imputamos, en relación con la demostración, que se sabe deductiva «y es reconocida cuando nos referimos a las "libertades"» ( $p$. 144). Otro ejemplo a mencionar sería el dolo como "resultado de la valoración de dicho conocimiento desde el punto de vista de la tipicidad concreta con la que se valora el hecho ya imputado" ( p. 145) - por el "dicho conocimiento" se refiere al conocimiento inicial valorado-. Se invita a el/la lector/a a descender sobre la profundidad de estas cuestiones planteadas fundamentalmente porque constituye una de las contribuciones con más referencias a la juridicidad y a la ciencia jurídica del Derecho penal desde la reflexión filosófica, enriqueciendo el carácter fenomenológico de muchas de las otras contribuciones.

Roberto J. Walton es el encargado de culminar la obra conjunta con una última contribución titulada "Monadología trascendental y derecho natural". 
Partiendo del gran volumen de publicaciones del autor y de la gran influencia que ha ejercido su trabajo en el seno de la comunidad fenomenológica, no resulta sorprendente que haya colaborado en la presente obra ofreciendo una brillante reflexión fenomenológica sobre Derecho natural. En una contribución a un curso sobre Ética y Filosofía del Derecho (1897) hallamos una sentencia muy interesante de Husserl en la que afirma que no se presta atención al Derecho "que nace con nosotros" (p. 155). El auge del positivismo jurídico en el campo de la filosofía del derecho muy probablemente redujera el Derecho a perspectivas naturalistas o simplemente históricas. De esta manera, asegura Walton, la crítica se extiende incluso a la concepción del Derecho natural propuesta por Reinach basada en un a priori que se encuentra lejos del a priori formal, que sería la propuesta de Husserl (p. 156). Resulta clave el análisis que realiza Walton en este punto. Sobre todo porque presenta la concepción estática que tuvo Husserl durante sus primeros textos en torno a la axiología y la práctica formal, comparándola con algunos textos de 1909 y las lecciones de ética de los años 20, donde el autor desarrolló “la axiología material y la práctica material” (p. 156). Gracias a este giro temático y metodológico se puede realizar una lectura orientada a explorar fenomenológicamente el Derecho en términos trascendentales si tenemos en cuenta que pueden haber "contenidos materiales a priori que pueden proporcionar la base para una normatividad" (p. 157). Estos contenidos materiales, dirá Walton, son la protohistoricidad y la historicidad racional que introduce una teleología histórica orientada hacia metas infinitas ( $p .157$ )

Una vez presentado el itinerario que guiará su contribución, se analizan cuestiones relativas a las vinculaciones entre Derecho y ética partiendo del curso que impartió Husserl a finales del siglo XIX. La ética vendría a configurarse como una disciplina científica y una preceptiva, siendo la preceptiva a su vez una dimensión dirigida a dilucidar los "más elevados fines de la vida y de las reglas para un ordenamiento racional de la vida y del obrar" (p. 157). Resulta interesante cómo el autor conecta la primera parte de la disciplina preceptiva -dedicada los elevados fines de la vida - con el Derecho natural, mientras la segunda parte estaría vinculada al Derecho positivo. La densidad de los análisis posteriores acerca cómo descansan las disciplinas normativas sobre las teoréticas parte de las investigaciones presentes en el texto de los Prolegómenos a una Lógica pura (1900), y se dirige, sobre todo, a dilucidar las relaciones entre las verdades teóricas y las normas en estadio pre-trascendental. Con ello se pretende esclarecer la región 
de las normas puras y el campo del Derecho natural "como ámbito subordinado a la ética" (p. 158). Siguiendo el planteamiento esbozado en la introducción, Walton analiza posteriormente la concepción de norma pura presentada por Husserl en las lecciones de 1908-1914; será la misma concepción que Husserl presentará en las lecciones 1920-1924 con unas ligeras variaciones. Téngase en cuenta en este punto la importancia del texto de "Renovación" de 1922-1923 porque es el lugar donde Husserl «se refiere ahí a "una 'verdadera y auténtica' humanidad" como una idea objetivamente válida conforme a cuyo sentido ha de reformarse la cultura que existe de hecho» (p. 160). La forma de cumplir con esta idea es la consolidación de lo que Husserl denomina una ciencia apriorística de las formas esenciales y leyes esenciales del espíritu, así como también las leyes de la espiritualidad racional (p. 160). Es a través del descubrimiento de la ciencia racional dirigida a descubrir la condición humana y las condiciones de su renovación que se pone de manifiesto cómo la caracterización teórica de un a priori material termina dando lugar “a formulaciones de carácter práctico" ( $p$. 161).

En las páginas que siguen, Walton analiza el procedimiento intrínseco a este movimiento histórico dado en la región de la protontología a través de una investigación autónoma denominada Historicidad, Derecho Positivo y Derecho Natural. En ella distingue una suerte de protohistoria (Urhistorie) encargada de las condiciones de posibilidad de la misma historia (p. 161) de una primera historicidad que refleja los procesos de institucionalización de los sentidos dados en una tradición particular. Incluso nos recuerda la presencia de una tercera historia denominada segunda historicidad basada en "una generatividad universal o racional" (p. 162). En este punto el análisis se torna esclarecedor desde el momento en que vincula las diferentes tipologías de historia hasta terminar reconociendo que el modo con el que se desarrolla la monadología trascendental "tiene su origen en una prohistoria y su meta en una segunda historicidad" (p. 162). De igual modo que dedica todo un epígrafe a la denominada protohistoricidad ( $p p$. 168-172) también dedica un extenso apartado a la segunda historicidad (pp. 172-181), sin olvidar los vínculos que presenta Husserl entre la primera historicidad y el Derecho natural, basados en la distinción general entre las formaciones culturales de la interacción humana y el Derecho (p. 164). No cabe duda alguna, como sostiene Walton, que este tipo de abordajes salen al encuentro a través de una determinada concepción del Derecho basada en la “autorización para 
coaccionar" (p. 164). Ello es comprensible si tenemos en cuenta que la fundamentación última "corresponde a la ética" (p. 166).

En cualquier caso, desde la operatividad de los niveles bajos en los que se inscribe el Derecho hallamos la referencia a la costumbre, que a su vez se divide en los siguientes niveles: (1) Sitte o costumbre, basado en normas reguladoras del comportamiento que son "transmitidas como aprobadas y exigidas desde afuera para la práctica habitual" (p. 167); (2) Derecho positivo, constituido a través de una racionalidad conforme a fines porque la forma reguladora surge de una voluntad que está dotada de poder (p. 167); (3) Sittlichkeit entendida como costumbre o costumbre virtuosa, es decir, costumbre donde el deber "está atado a una comunidad de juicio moral" (p. 167). Ahora bien, más allá de estas cuestiones que operan en la vía de la costumbre hallamos en el texto del autor algunas vías señaladas por Husserl. Por un lado, nos topamos con la vía de la protohistoricidad. En esta vía de examinación de las condiciones de posibilidad de la misma historia ha de tenerse en cuenta el derecho natural a la preservación de la tierra ( p. 169) por haber sido cuestionado desde la perspectiva de la explotación por Jan Patočka. Asimismo, también ha de tenerse en cuenta que la protohistoria siempre se encuentra ligada a lo que Husserl denomina progeneratividad o sucesión periódica de las generaciones "en virtud del nacimiento y la muerte" (p. 169) en las cuales juegan un rol fundamental los mismos instintos vitales. Haciendo confluir los dos puntos es entendible que Walton incluya en este punto el "derecho natural a la preservación de la protogenerativdad" ( $p .170)$, vinculado a "un derecho natural al acogimiento en un hogar" (p. 172). Por otro lado, también tenemos acceso por medio de la vía de la segunda historicidad "caracterizada por una generatividad universal frente a las limitadas formas culturales de la primera historicidad" ( p. 172). Así como en la vía de la protohistoricidad la preservación de la tierra se manifestaba en el derecho al hogar, en este caso nos hallamos frente un Derecho natural a la preservación de la tierra dirigido a no hacer desaparecer la tierra "bajo una vestimenta de construcciones" (p. 173).

A continuación, el autor incorpora la teoría de Leibniz sobre las reglas del Derecho natural -entendidas como reglas que no tienen excepciones y que son inmutables (p. 173) - así como también la teoría kantiana de los deberes jurídicos fundamentada en un derecho natural que incorpora la justicia distributiva conocida a priori (p. 174). Ahondando en los análisis comparados y en las cuestiones filosóficas de fondo, termina afirmando que para Husserl "dar a cada uno 
lo suyo antecede a toda consideración de índole jurídica" (p. 174) en la medida en que se fundamenta en aquella región de trascendentalidad que opera en el contacto intersubjetivo. Walton mencionará a esta región "las operaciones trascendentales que hacen posible la experiencia con el otro" ( p. 174) y servirá de base al autor para confrontar en las siguientes páginas las aproximaciones de Kant, Leibniz y el mismo Husserl (pp. 175-181). Finalmente elabora un apartado titulado Fenomenología, Filosofía trascendental y Derecho natural donde hace aterrizar la filosofía fenomenológica de Husserl sobre la corriente del Derecho natural en sus diferentes manifestaciones epocales. Esto quiere decir tomar en consideración las tres direcciones principales: dimensión antropológica, cosmológica y la relación entre una ley natural y la ley eterna "bajo la forma de un vínculo entre las metas de la historia racional y una teleología guiada por Dios" (p. 182), sin olvidar la ineludible influencia de la legalidad kantiana por las conexiones explícitas que encuentra el Derecho natural con la libertad y su uso exterior (p. 185). Termina por afirmar que la orientación fenomenológica se halla próxima a las posiciones “que conciernen a la relación pretensión-obligación, a un Derecho natural como marco regulador, al mínimo deber respecto del otro y a la comunidad del amor" (p. 185), vinculando el análisis de Husserl con la perspectiva de Reinach, tendiendo puentes con Max Scheler e incluso desde la fenomenología existencial de William A. Luypen, lo que confiere a la contribución de Walton un elemento de heterogeneidad que enriquece sumamente las aportaciones del resto de autores/as colaboradores/as en el presente volumen.

\section{CONSIDERACIONES FINALES}

A propósito del carácter íntegro de las contribuciones debe tomarse la presente obra como una de las principales referencias para analizar fenomenológicamente el Derecho desde la perspectiva del iusnaturalismo clásico o Derecho natural. Prueba de ello es la escasa literatura existente en la materia y la lograda interconexión de los problemas planteados. En este sentido, la ausencia de un análisis profundo sobre el Derecho en las obras de Husserl no es un impedimento para explorar el campo de lo jurídico. Aún hallando en la obra de Reinach algunos análisis fundamentales, algunas de las descripciones elaboradas demuestran la posibilidad de continuar la propuesta a priori de Reinach de modos muy diferenciados. Precisamente porque la obra surge a raíz de la ausencia de contribuciones 
al respecto ha de reconocérsele a los autores el rigor que imprimen las investigaciones, lo cual atribuye a la obra un determinado carácter propedéutico capaz situar al/la lector/a en un estado de la cuestión preciso y acertado, al mismo tiempo que lo reconduce a los textos del mismo Husserl, avivando así su legado y dejando abierta la puerta a futuros/as investigadores/as.

\section{BIBLIOGRAFÍA}

CRESPO, M. (2018). Filosofía trascendental, Fenomenología y Derecho Natural. Hildesheim: Georg Olms.

-, (2016). “Fenomenología y filosofía del derecho”. Pensamiento, 72 (274), 1247-1261.

-, (2016). “Derecho Natural y Fenomenología. Una aproximación desde las ideas de Hans Reiner", En Cianciardo, J. \& Zambrano, P. (Coords.). Razón Práctica, Autonomía y Derechos Fundamentales (pp. 19-35). Ciudad de México: Tribunal Federal de Justicia Administrativa. 